\title{
CSR standards and guidelines: An Analytical review
}

\author{
Alpana \\ (Assistant Professor, SRCC, University of Delhi)
}

\begin{abstract}
The notion of corporate social responsibility has advanced from simply fund raising events by organizations to making them accountable to different stakeholder groups who are associated with the organisation. The push is now on creating a shared value in which the social needs are integrated in a business model so as to satisfy the facets, profitability and service to the society. To help organisations in developing and implementing their social responsibility practices various national and international voluntary guidance notes on social, environmental and economic responsibilities are available. Such guidelines include ISO26000, GRI G3.1 Sustainability Reporting Guidelines, Accountability's AA1000 Standard, National Voluntary Guideline, UN Global Compact, CSR: An Implementation guide by IISD. These guidelines are developed with the objective to provide enlightening guidance to organization, in order to achieve new paradigm in CSR. This paper analyses all these guidelines that set down the framework to help the organizations in developing their CSR practices and how the organisations should go about implementing the practices developed.
\end{abstract}

Keywords: CSR, ISO 26000, IISD Guide, AA1000 SES, NVG, GRI.

\subsection{Corporate Social Responsibility (CSR)}

\section{Introduction}

Corporate Social responsibility (CSR) has become a key issue for today's corporations. This type of responsibility refers to the continuing commitment of businesses to voluntarily behave ethically and contribute to social, economic and environment development while simultaneously improving the quality of life of the workforce, families, local community and society at large.

Carroll, (1991): The CSR pyramid is based on a four-part perspective, namely economic, legal, ethical and philanthropic standpoint. A four-part conceptualization of CSR includes the "idea that the corporation has not only economic and legal obligations, but ethical and discretionary responsibility as well"

\subsection{ISO 26000 Guidelines for social responsibility}

\section{Guidelines and standards}

International organization for standardization is the world's leading developer of international standards. The standards are designed by ISO to be implemented worldwide. It was established in 1926 and its secretariat is situated in Geneva, Switzerland. ISO launched the ISO 26000 Voluntary guidance on social responsibility in 2010 . The guideline is prepared by ISO and technical member working group on social responsibility.

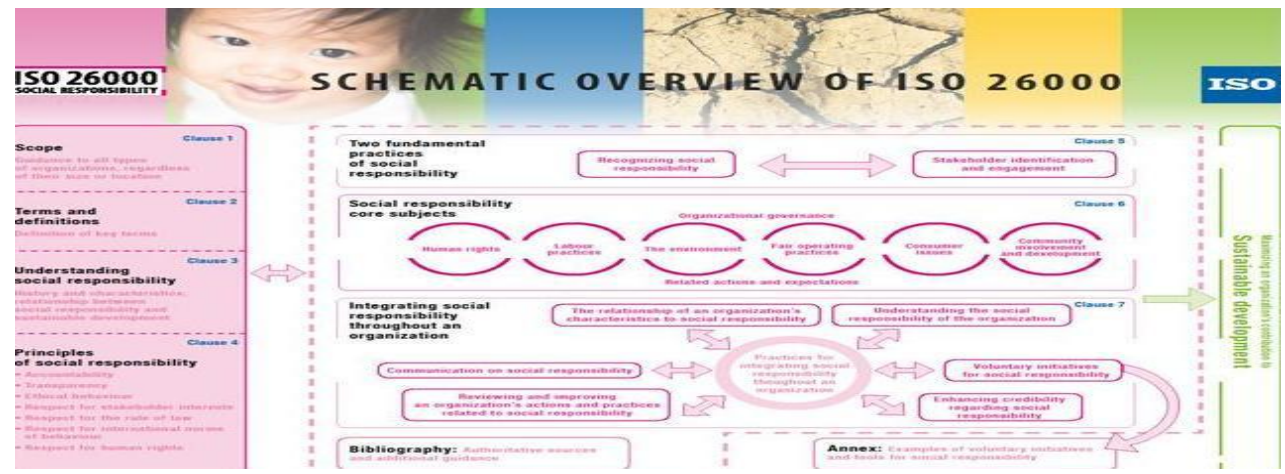

This Guideline is meant for all types of organizations and their size and location also does not matter. The standards were developed by using a multistakeholder approach which means the advice of experts from 90 countries and 40 international or broadly based regional organization involved in it. These experts were from different stakeholder groups namely consumers, government, industry, labor, non-governmental organization and service support, research academics and others. The guideline is aimed to help the organization to operate in a social responsible manner and also meet the need of the society. 
The ISO 26000 contains the guidelines so there is no requirement of certification like other standards. In 2004, when the process of ISO 26000 Standard development was about to commence International Institute for Sustainable Development, The International Institute For Environment and Development, IUCN - The World Conservation Union, The African Institute Of Corporate Citizenship, Development Alternatives and Recourses e Investigación para el Desarrollo Sustentable issued a briefing note to present a general overview of three issues that deserve particular attention in discussions on the possible development by the International Organization for Standardization (ISO) for international Social Responsibility standards. In briefing note they deal with issues related to small and medium-sized enterprises (SMEs); stakeholder capacity to engage in corporate social responsibility (CSR). They depicted the links between the approach of multi-stakeholder engagement within the corporate social responsibility (CSR) agenda and the development of any ISO output on social responsibility. They addressed the links in two ways first by looking to the theme of multi-stakeholder engagement to inform development of an appropriate process for CSR-related work within ISO and its member bodies. Second to help, learn about future discussions on how the content of any ISO output might itself address multi stakeholder engagement. They suggest that in standards development, ISO will need to provide -opportunitiesll for stakeholders to participate in the development of any ISO CSR-related output and It should necessitate to go ahead to help to create the circumstances in which those opportunities are likely to be realized. ISO's processes will also need to deliver outputs that are capable of providing or at least pointing to meaningful guidance to businesses on how to manage stakeholder engagement. In the briefing note they also suggest that it should be prime objective of principle that at a time when the content of any CSR-related outputs is uncertain, the guiding principle supposed to be discovered and integrate best practice processes of multi-stakeholder engagement, they further explained that If CSR-related standardization is not based on sufficient multistakeholder engagement, there are likely to be two consequences.

1. Any resulting CSR related standard will possibly lack credibility among some stakeholder groups that is basically shaped by social expectations of businesses.

2. There may be less likely to include good advice on stakeholder engagement, which can make it less valuable to those organizations that it addresses, and so deteriorate who adopt its. Advisory Group on Social Responsibility recommended that ISO should review its processes and, where necessary, makes adjustments to ensure meaningful participation by a fuller range of -interested partiesll. The ISO's Standard developing working group took these suggestion into consideration at the time of developing standard and they developed the standards after engaging multistakeholder in the development process, there were 6 member from each countries, and they were representing different stakeholder namely Consumer, Corporate, NGO's, IGO's etc. The result of the maultistakeholder consultation in the ISO WG/SR is there to see in the ISO26000 which is formidable explicitly state guideline for Social Responsibility of all types of organization.

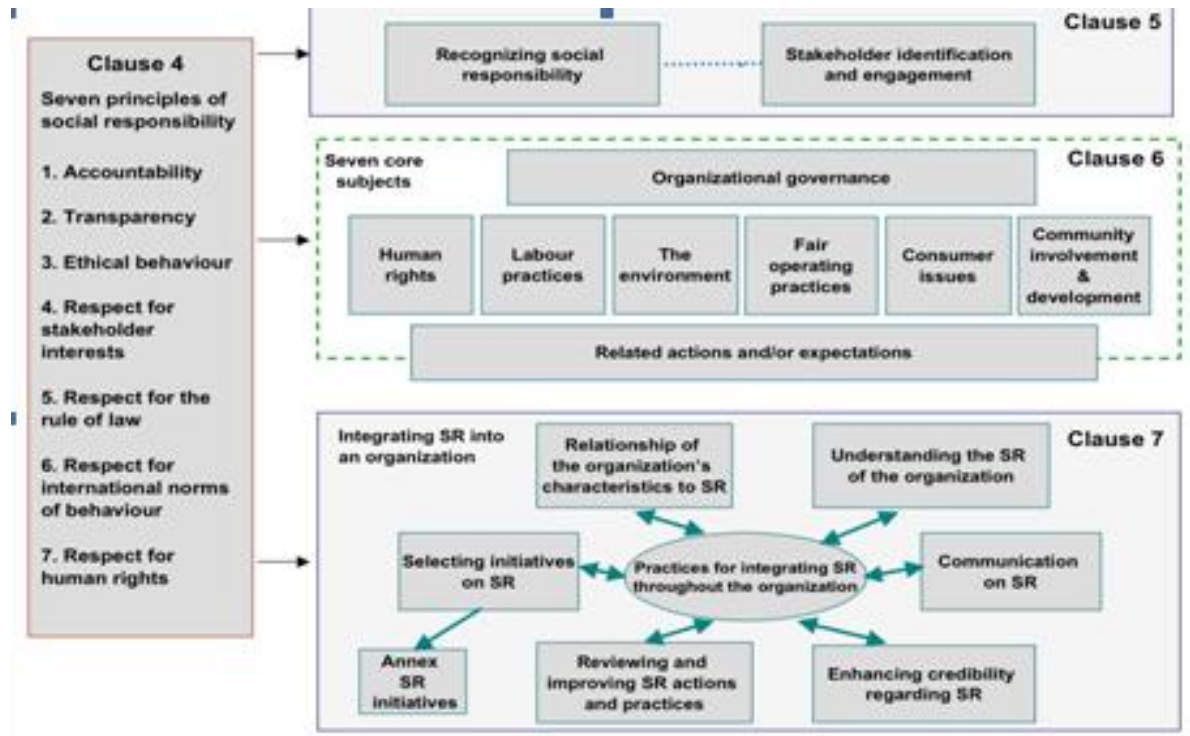


ISO 26000 contains the following contents: -

* Introduction,

* Clause 1- Scope,

* Clause 2- Terms And Conditions,

* Clause3- Understanding Social Responsibility,

Clause 4- Principles Of SR,

* Clause 5- Guidance On SR Core Subjects,

* Clause 6 - Guidance On Integrating SR Throughout An Organization,

* Annexure A- Examples of Voluntary Initiatives and Tools for SR.

* Annexure B- Abbreviated Terms,

Bibliography - Includes the referent instruments and ISO standards that are referenced in the body of these intervention standards as source material.

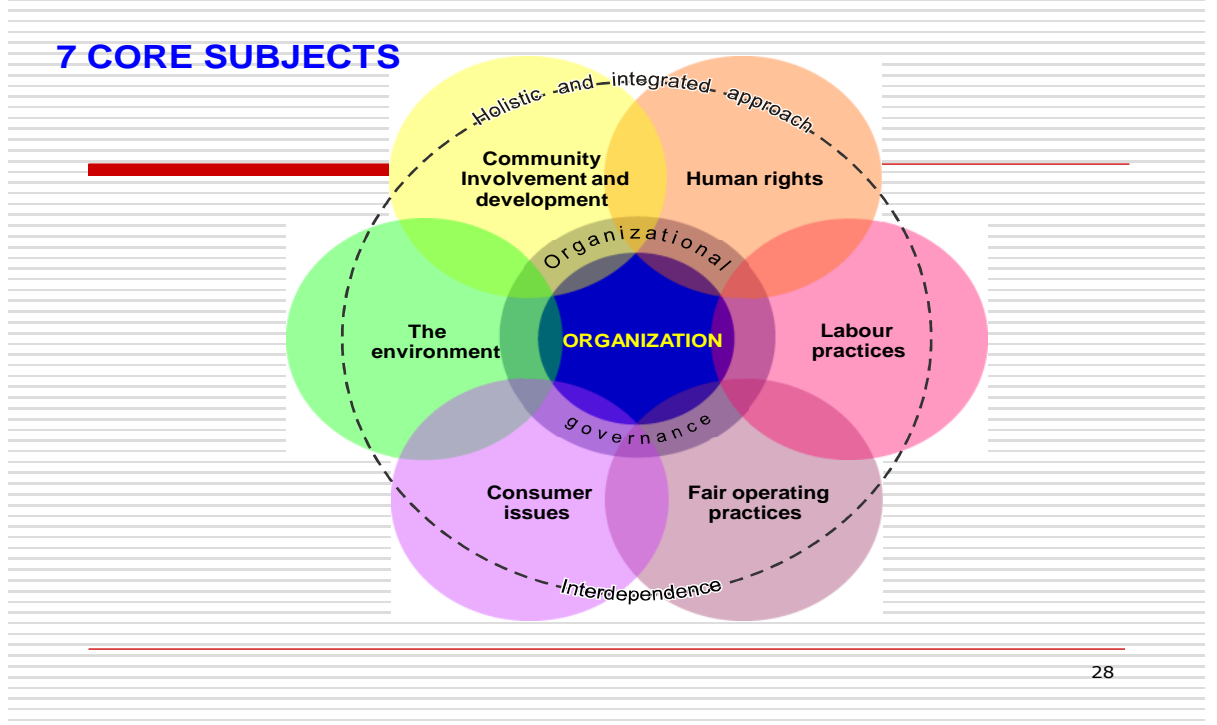

Organization and their stakeholder are becoming aware of the need of sustainable development and also the need to behave in a socially responsible way, No business can operate profitably without considering the expectations of its stakeholders and the environment, both are these very important stakeholders of the organization. Organization does not work in vacuum they are also interconnected and dependent on other environment aspects. The basic idea of ISO is to provide guidance on the underlying principle of social responsibility, recognizing social responsibility and engaging stakeholder the core subjects and issue pertains to $\mathrm{SR}$ and on ways to integrating to $\mathrm{SR}$ and on ways to integrate socially responsible behaviors into the organization.

\subsection{National Voluntary Guidelines}

The Importance Of business in the society is well recognized and understood by the whole world. People are getting aware of the fact that business can play a significant role in betterment of the quality of life and in today's complex environment. It can lead to spread the long -lasting impacts on people, our planet and also able to help in aspire the sustainable development. But all these can be achieved only when the business functions with fairness, responsible and ethical manner. So the concern for the fair, transparent and ethical behavior adopted by the business has also increasing among the stakeholders. So to help the business houses and to motivate them to engage in socially responsible business the Indian Government also took an effective step by launching the voluntary guidelines on CSR in 2009. It was the first step towards the concept of Business Responsibility (BR). But after getting the useful feed backs from many diverse stakeholders, Ministry of corporate affairs launched the refined and improved Guidelines over the earlier CSR Voluntary guidelines 2009 named as National voluntary guidelines on Social, Environment and Economic Responsibilities of business. Even though Stakeholder consultation was claimed, a number of stakeholders includes representation of consumer were never consulted during this process. This guideline is based on the perspective of only some stakeholders. It presents the basic requirements for business to function in a responsible manner in order to achieve the wholesome and inclusive economic growth. The guidelines are not 
prescriptive it is based upon the practices and earlier available evidence and its real life cases of Indian business houses. Its main idea is to motivate the business to use triple bottom line approach of SR so the business financial condition can be harmonized with the society, environment and stakeholder's benefits. Its core idea is to enhance the socially responsibility (SR) practices in India. Adoption of these guidelines into practice will help the business to enhance the competitiveness, profit and better human resource management. These guidelines are easy to understand and implement. The guidelines have been formed in 9 principles with core elements to support the each principle and with each principle a sections also have been given to help the management implementations of these SR practices in the business. Even though they were prepared without full range of consultation (including consumer).

Principle 1. "Businesses should conduct and govern themselves with Ethics, Transparency and Accountability"- This principle states that the ethical conduct in all activities and functions should be the fundamental idea of the responsible business it explain, that there is a clarity and fairness in all the activities of the business and they should report or disclose the all actions so that the stakeholders can be aware and results are visible to them. It also recognize that there is an act distribution of responsibility and power so the accountability of each person should be clears and noticeable.

Principle 2: "Business should provide goods and services that are safe and contribute to sustain ability throughout their life cycle"- This principle explains that the business should work to improve the quality of life of and it should design its activities and functions which enhance the profitability to the business but also contribute to the realm of SR concern. The all stages of product life cycle has some direct or indirect impact on the society so at the time of making decision form procuring raw material to disposal of goods/waste the stake of society should be kept in mind. The business should not only take care about their internal activities but try to go beyond and also keep eye on the external activities to ensure the betterment of the society as a whole.

Principle 3: "Business should promote the well being of all employee"- It states that business should take the well being of all the employees connected with it value chain at the time of making and implementing the policies and practices. And this could be applicable for all types of employees whether they are in or outside of the business or they are subcontracted workers. Its core elements suggest that business should provide and respect the freedom \& rights of employees for example freedom of association, participation, addressable mechanisms. It's should mountain the equal opportunities environment for all employees.

Principle 4: "Business should respect the interest of and be responsible towards all stakeholders, especially those who are disadvantage vulnerable and marginalized"- This principle states that business should go beyond the boundaries means It should not take care about the interest of its shareholders but also consider the stakeholder, especially those who are less aware, under privileged and in a marginal or in vulnerable positions in the society

Principle 5: "Business should respect and promote human rights"- This principle recognizes that business should protect, promote and respect the human rights because these rights are the fundamental need of the human and these are evolved under the heading of civil, political,

Cultural and social rights. That business's who respect and promote these, they are able to gain profit, opportunity and widens acceptance from the society.

Principle 6: "Business do should respect, protect and makes efforts to restore the environment"- This principle states that business should take care about the environment and its various dimensions because it is the first important responsibility of business to take care. This principle explains that environmental sustainability is the top responsibility because it is important for, economic growth and society's benefit as well. It also explains that environmental issues are very important part of the environment it also encourage business to understand and be accountable for those activities directly or indirectly affect the environment.

Principle 7: "Businesses, when engaged in influencing public and regulatory policy, should do so in a responsible mannerl- This principle states that the business should follow all the laws and rule of regulation because these are made by and for the various stakeholder so at the time of making policies and conducting various activities the concern for all the rules and 
policies should be there.

The core element attached with suggest that

a business should recommend those polices which are according to the given principle and guidelines and for this the business should take help from the various trade and industry chambers and association.

Principle 8: "Business should try to participate in the inclusive growth motive"- In India the disparity in growth level in various sections is very drastic so to overcome this problem every business should take care to help and make strong the various underdeveloped and marginalized sections and for this they can join hand with various government or non government agencies. Equitable and inclusive growth definitely helps the business to grow.

Principle 9: "Businesses should engage with and provide value to their customers and consumers in a responsible manner"- The principle states that basic aim of a business entity is to provide goods and services to its customers in a manner that creates value for both. Consumers are one of important stakeholder of the business and no business can survive without making the satisfied. In today's era customer is consider as the king of the market. The principle recognize that no business firm even can exist or survive in the absence of its customers. The principle state that customers enjoy the freedom of choice in the selection and usage of goods and services so it is the duty of the enterprise to produce and provide desired product and services to the consumer and that should safe, at competitive priced, easy to use and safe to dispose off, for the benefit of their customers. The main objective of the principle is to protect the interests of the consumer.

The customer delight is the new approach now days which means provides the extra value which actual expecting by the customer. Principle Nine explains that businesses have a responsibility to cultivate the long term adverse impacts that excessive consumption may have on the overall well-being of individuals, society and our planet. They promote sustainable consumption. The core elements attached with this principle states that Businesses, should take into account the overall well-being of the customers and that of society at the time of fulfilling the need of the customer and it should try to make it sure at the time of designing, promoting and selling their products, the rights of the freedom of choice and free competition in any manner should not restricted by their activities. This principle also suggests business to disclose all information truthfully reliably, transparently and factually, through labeling and other means. All the information should be clearly mentioned on the labels which includes the risks to the individual, to society and to the planet from the use of the products, so by which the customers can do exercises their freedom to consume in a responsible manner.

Business should carry the awareness program when the need is required as in India people are less aware about their rights so it is the duty of the responsible business to make their customer aware so they can enjoy their full rights and also take care about making choices of product. Businesses should promote and advertise their products in ways that do not mislead or confuse the consumers or violate any of the principles in this Guideline. It should take care and caution while providing goods and services that result in over exploitation of natural resources or lead to excessive conspicuous consumption. For example products are made by those natural resources which are non-renewable by the nature or product the which can harm the safety and security like destructive weapons, and there should be good grievance handling mechanism which can handle the grievances of customer on timely and adequately basis and also provide necessary information to the customer which are important for them and a good two communication channel also set up the business which provide information along with important feedback from the customer.

\subsection{IISD Guide on CSR}

This CSR guide is developed by International Institute for Sustainable Development (IISD). Today the need for sustainable, just and balanced development is required but with protection of natural system and environment. The need for the information, examples of company who are using it and advice about CSR is raised so this guide is basically meant to help those interested organizations who wants to implement the CSR approach in their organization, This CSR guide is based on the guide prepared by the Canadian government and its basic agenda is to provide guidance to the companies and Institution about how to operate in socially responsible manner. Many governments, non-government, multilateral organization and many other groups have contributed their useful time \& energy to development of this guide. It is basically provide the information available in the market place.

The purpose of the guide is to provide the early assessing information on CSR so the Guide is drawing on the already developed CSR instruments and initiatives and their respective names are following.

(1)The organization for economic co-operation \& development for multination enterprises (OECD)

(2) The UN Global compact 
(3).The Global Reporting initiative (GRI)

(4). The International Organization for Standardization (ISO)

(5). The Account Ability AA1000 Standard.

This guide is only developed for providing the information on available CSR Instruments. It does not suggest only sticking with them because CSR is a dynamic issue so the organization should change their strategy as per the required situation. The guide extracts ideas and processes from a variety of sources, and is intended to be suggestive, not prescriptive. It has three parts. Part 1 of this guide is an overview of CSR -- how it is defined, the business case for it and the relationship between CSR and the law. Part two of this guide sets out a six-stage "plan, do, check and improve" implementation framework for a CSR approach. This part also features information particular to small business. Part three of this guide looks at stakeholder engagement and the integral role stakeholders can play in implementing an effective CSR approach. Five appendices contain supplementary information, including a list of key sources for further reading. The business is the center of the society. It is not only playing a significant role to earn profit but it also plays a central role for betterment of the society. Part two of IISD guide on CSR explains about the implementation process of CSR Implementing corporate social responsibility- it is explained in the guide that there is no =one particular method for each type of firms for implementing a corporate social responsibility (CSR) approach'. Each firm has distinctive quality and situation that will affect how it analyse its social responsibilities. Everyone will vary in its awareness of CSR issues and how much work it has already done towards implementing a CSR approach. That is explained in guide that, there is a considerable value in proceeding with CSR implementation in a systematic way -- in harmony with the firm's mission, and sensitive to its business culture, environment and risk profile, and operating conditions. CSR is not only is good for society but it also makes profit for the business too.

This guide proposes an implementation framework comprising six key tasks as follow

\begin{tabular}{|c|c|c|}
\hline \multirow[t]{2}{*}{ Plan } & $\begin{array}{l}\text { 1.Conduct a CSR } \\
\text { assessment }\end{array}$ & $\begin{array}{l}\text { - } \\
\text { - } \\
\text { - } \\
\text { Develop a working definition of CSR } \\
\text { Identify and engage key stakeholders }\end{array}$ \\
\hline & $\begin{array}{l}\text { 2. Develop a CSR } \\
\text { strategy }\end{array}$ & 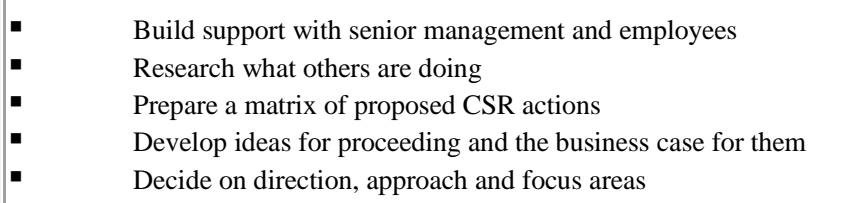 \\
\hline \multirow[t]{2}{*}{ Do } & $\begin{array}{l}\text { 3. Develop CSR } \\
\text { commitments }\end{array}$ & $\begin{array}{l}\text { - } \quad \begin{array}{l}\text { Do a scan of CSR commitments } \\
\text { - }\end{array} \quad \begin{array}{l}\text { Hold discussions with major stakeholders } \\
\text { - }\end{array} \quad \begin{array}{l}\text { Preate a working group to develop the commitments } \\
\text { - }\end{array} \quad \text { Consult with affected stakeholders }\end{array}$ \\
\hline & $\begin{array}{l}\text { 4. Implement CSR } \\
\text { commitments }\end{array}$ & 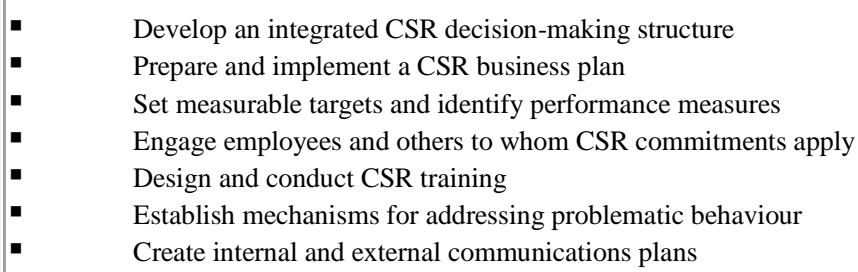 \\
\hline Check & $\begin{array}{l}\text { 5. Verify and report } \\
\text { on progress }\end{array}$ & $\begin{array}{ll}\text { - } & \text { Measure and verify performance } \\
\text { Engage stakeholders } \\
\text { Report on performance }\end{array}$ \\
\hline Improve & $\begin{array}{l}\text { 6. Evaluate and } \\
\text { improve }\end{array}$ & $\begin{array}{ll}\text { - } & \text { Evaluate performance } \\
\text { - } & \text { Identify opportunities for improvement } \\
\text { Engage stakeholders }\end{array}$ \\
\hline $\mathrm{C}$ & completed & Return to plan and start the next cycle \\
\hline
\end{tabular}


Source: IISD Guide

The third part of IISD guide explained the importance of stakeholder engagement what is stakeholder engagement? At its most basic, CSR is about seeing business as an integral part of society, the global community and the environment that supports it.

A five-step stakeholder engagement process is given in the IISD guide as follow:-

1. Identify stakeholders

2. Understand the reasons for stakeholder engagement

3. Plan the engagement process

4. Start the dialogue

5. Maintain the dialogue and deliver on commitments.

\subsection{AA1000 Stakeholder Engagement Standard 2011}

ThisAA1000 Framework Standard was first published in 1999, in this standard the first principle introduced is inclusivity and it is basically the participation of stakeholders in developing and achieving a liable and planned response to sustainability. This standard states that stakeholder engagement is an instrument that organizations use to achieve inclusivity and to support this, the standard include the guidance about the design and method for how to conduct stakeholder engagement in the 1999 AA1000 Framework Standard. AA1000 stakeholder engagement standards states that stakeholder engagement concept is basically not new it is just emerged as a very important approach recently for gaining sustainability and success for the organization. The basic purpose of making this standard is to establish the benchmark for good quality engagement. The AA1000 SES standard explains that stakeholders are not just members of communities or nongovernmental organizations. They are those individuals, groups of individuals or organizations that affect and or could be affected by an organization's activities, products or services and associated performance with consider to the issues to be addressed by the engagement. Stakeholder engagement is the process used by an organization to engage relevant stakeholders for a clear purpose to achieve accepted outcomes.

The AA1000 SES (2011) consists of four parts. The first part describes the purpose and scope of the standard. It clear who the proposed users are, making it clear that while this standard is primarily intended for practitioners and engagement owners, it will be of significant use to all those involved in engagement as well as all who will benefit from and also makes clear that the standard is for all type and size of organizations.

The second part of the guideline explains about the commitment and incorporation of stakeholder engagement. The guidelines explained that stakeholder engagement must be implanted in the culture and core functions of the organization. To achieve this, principle and integration of stakeholder engagement with organizational governance, strategy and operations. Through this commitment and integration, the outputs of stakeholder engagement lead to strategic and operational outcomes. The standards explain that Inclusivity, materiality and responsiveness requires a defined process of stakeholder engagement that provides complete and fair involvement and results in outcomes that tackle and react to issues and impacts in a responsible way. The third part of standard talks about the Purpose, Scope and Stakeholder- The standard explained that winning engagement depends on understanding why to engaging (the purpose), what to engaging on (the scope), and who needs to be involved in the engagement (ownership, mandate, stakeholders). The standard further suggest and explained that dedication to the AA1000 APS (2008) principles and the incorporation of stakeholder engagement into governance, strategy and operations require stakeholder engagement to be used systematically and regularly across the organization. The fourth part of the standard talks about the main focus of the guideline means the stakeholder engagement first in this part the Process of stakeholder engagement is given. Stakeholder engagement process includes four stages: Plan; Prepare; Implement; and Act, Review and Improve.

\subsection{Other Global instruments of CSR}

1. OECD Guidelines-The OECD is an international inter-government economic organization of 34 countries founded in 1961 to stimulate economic progress in the world. It has long standing governmental co-operation and it provides a broader framework for International investment and address a wide range of issues namely (1) Accountability (2) Business conduct (3) Community involvement (4) corporate governance (5) environment (6) Human Rights (7) consumers' protection and (8) labor relations. It is highly focused at activities within individual adhering countries and their affects depend mainly upon on that on the 33 adhering countries, National contact points (Government).

2. UN Global compact- It is first purposed by the UN. Secretary Kofi Annan in 1999, in the form of 10 principles \& now promoting and endorsing by the different UN secretariats and companies. UN global compact addresses 6 of the 8 broader issues and areas of business ethics. For ensuring and safe guarding the sustainable growth, business are asked to contribute to the effectives of Global compact by (a) taking lead in corporate 
Citizenship. (b). Embracing \& enacting the principals of the global compact. (c). Working with UN agencies. (4). Advocating a strong UN and It also seek the endorsement components. Since the Global compact was launched in 1999, a number of more detailed and comprehensive guidelines have come into being which incorporate the ten GC principles. Therefore, If we follows ISO 26000, IISD Guide, AA1000 and GRI.3 then adherence of GC separately is not required as these instruments incorporates the GC ten principles as well. 3. Caux principle for Business- It is formed in 1986 by the group of senior executive from major MNE's and they have their headquarters situated in Europe, Japan and North America. It deals with the broader area of business ethics namely- (1)Accountability (2) Business conduct (3) Community involvement (4) Corporate governance (5) Environment (6) Human Rights (7) Consumers protection and (8) labor relations. Caux principle and Global corporate responsibility benchmark-No formal promotional procedure so this global instrument only influence to think about the global CSR but not able to link up the concerned parties.

4. Global Corporate Responsibility: Benchmarks - the guideline was first launched in march 2011 in South Africa and it a non-denominational alliance of religious groups based in the US, UK \& Canada the Benchmark is the top guidelines covered the major Issues of business ethics. It has no-formal promotional procedure so this Global instrument only influences to think about the global CSR but not able link up the concerned parties.

5. Global Sullivan principles- The principles were launched in 1999 by Rev. Sullivan and United Nations secretary Kofi Annan. The new and expanded corporate codes of conduct were designed to increase the active participation of corporations in the advancement of human rights and social justice at the international level. Reverend Leon Sullivan, well known anti apartheid activists. It requires the initiatives of the companies for endorsing principle.

6. Global Reporting initiative- The GRI is a non-profit organization that promotes economic and developed by a broad alliance of diverse organizations \& partially funded by the U.N Environment program. It produces one of the world's most prevalent standards for sustainability reporting also known as ecological footprint reporting, environmental social governance and triple bottom line reporting and corporate social responsibility reporting. GRI seeks to make sustainability reporting by all organizations as routine as, and comparable to, financial reporting. It requires the self initiative of the companies for endorsing principles. The GRI is one of the most comprehensive documents which guide organization on how to report their CSR activities. It can be used as a supplementary tool by companies which are implementing NVG in India.

7. SA 8000- It is an alliance of Trade unions, NGO \& business. The SA8000 are complying the Transparency human rights and Labor rights seek to help companies with the management \& Reporting phases of their corporate responsibility initiatives. So they require external certification Agencies or organization. -Seek to help companies with the management \& reporting phases of their corporate responsibility initiatives. So they require external certification Agencies Organization.

\section{Conclusion}

The national and international guidelines reviewed in the paper suggest the basic code of conduct, through which organizations can attain the objectives of social responsibility. ISO-26000 Guideline on social responsibility is an excellent tool in this area; it provides wide explanatory knowledge in the form of 7 core principles namely Human rights, The environment, Labour practice, Consumer issue, Fair operating practices, and community development. This guideline explains each important core subject in a very explicit manner. ISO-26000 is one of the best available guidelines on Social Responsibility internationally. The corporate social responsibility guide developed by institute for sustainable development (IISD) is also one another available material on corporate social responsibility. The purpose of this guide is to provide the early assessing information on CSR, it is actually developed with the use of available global instruments namely- Caux Principle, The GRI, ISO, AA1000, OECD Standards, And The UN Global Compact. It provides a good framework to understand and implement CSR in the organization and it also provides a good design of Stakeholder Engagement. The AA1000 standard for stakeholder engagement is also a good initiative in this area. The main focus of AA1000 guideline is to help the organization in integration of stakeholder engagement in the organization's strategy development and operational activities. It consists of all the information which can lead to achieve a good stakeholder relation in order to enhance the monetary value with the good image build up in the society.

Indian Government also took this approach seriously and launched the National Voluntary Guidelines in 2011. It is noted here that the principle nine on consumer stakeholder expectation is not adequately elaborated. This is due to lack of consultation with representatives of consumer during the elaboration process of these guidelines. These National Guidelines only elaborate the principle which business are expected to address their CSR practice. NVG, however, do not provide for 
the detailed elaboration of stakeholder engagement process, the Corporate Governance mechanisms to manage the CSR practices as well as mechanism for creation of CSV. To that extent NVG are not a self contained code to manage CSR. Therefore, companies expected to implement $\mathrm{NVG}^{\text {'s }}$ are well advised to also take guidance from ISO 26000, AA1000, GRI.3, and the IISD guide on CSR which have also been discussed in the former sections.

These guidelines were framed to help each type of organization in implementation of Social Responsibility practices in their business. But overall the IISD guide and ISO-26000 guideline contains the most useable knowledge and information because they gather the contribution of each type of stakeholder on the other hand NVG was developed on the basis of available business examples and there was little involvement of stakeholder in its elaboration. The NVG is a tool that provides guidance on 9 core principles for CSR activities. However, it doesn't provide practical guidance on creating shared value or stakeholder engagement, in CSR planning and implementation. Therefore, it will be useful For Indian companies to use ISO-26000, AA1000, and GRI.3 as supplementary tools for implementation and report CSR based on National Voluntary Guideline (NVG).

A. Article:-.

\section{Bibliography}

[1]. A Carroll, The Pyramid of Corporate Social Responsibility: Toward the moral management of organizational stakeholders, Business Horizons, 34,1991, 39-48.

\section{B. Report \Guidelines:-}

[1]. International Standard ISO 26000 Guidance on —-Social responsibility\| issued by ISO on 2010(E)

[2]. CSR: An implementation guide for business \| issued by IISD by ISO on 2007.

[3]. Briefing Note on Stakeholder Engagement, ISO and Corporate Social Responsibility issued by International Institute fo Sustainable Development, May 2004.

C. Internet Resources:-

[1]. http://www.mca.gov.in/Ministry/latestnews/National_Voluntary_Guidelines 20 11_12jul2011.pdf

[2]. http://www.accountability.org/standards/aa1000ses/index.html 